\title{
Progress in the treatment of transposition of the great arteries
}

\section{St Cyres Lecture delivered at the Royal College of Physicians, 1972}

\author{
R. E. Bonham-Carter \\ From the Thoracic Unit, The Hospital for Sick Children, Great Ormond Street, London
}

This is a report on the progress in the treatment of transposition of the great arteries from 1956 to 1972 at the Thoracic Unit, The Hospital for Sick Children, Great Ormond Street, London. It reviews the results of palliative as well as 'corrective' procedures, from which an outline of future management may be deduced.

The complexity of the anatomical variants and the number of anatomical classifications of these make it necessary at the outset to define the lesion that this lecture is about. It is the condition in which the aorta arises wholly from the systemic venous ventricle and the pulmonary artery wholly from the pulmonary venous ventricle, and in which these ventricles are not inverted. To this lesion must be added the presence of atrial septal defects, ventricular septal defects, persistent ductus arteriosus, and obstruction to the outflow of the pulmonary venous ventricle, for these additional lesions have effects upon the natural history and influence the surgical treatment (Bonham-Carter, 1967).

\section{Natural history}

The natural history of transposition of the great arteries as defined above is such that of those without additional communications between the systemic and pulmonary circulations some 80 per cent will be dead before the age of 6 months, and nearly 90 per cent by the age of I year (Liebman, Cullum, and Belloc, 1969; Boesen, 1963; Hoffheinz, Glaser, and Rodewald, 1964). Liebman further shows that when additional communications are present this prognosis is improved. So in transposition of the great arteries + ventricular septal defect some 30 per cent may be expected to live for 6 months, and about 20 per cent for a year. The best outlook is for these two anomalies together to be associated with

Received 15 December 1972. left ventricular outflow tract obstruction where after an initial death rate of 25 per cent in the first three months 75 per cent live at least for the first year and many much longer. The effect of the presence of an atrial septal defect upon the natural history is best shown by the result of balloon atrial septostomy. Tynan has shown that after balloon atrial septostomy 75 per cent may be expected to be alive at 6 months and 65 per cent at I year (Tynan, 1968, I97I). It is probable that the prognosis of transposition of the great arteries with naturally occurring atrial septal defect will be similar. Tynan also showed that the high mortality in the first week of life was commonly associated with other cardiac defects, notably coarctation of the aorta (Tynan, 1968, I97I). Carr (quoted by Bonham-Carter, 1967) showed that the benefit obtained by the presence of an atrial septal defect was due to a bidirectional shunt at atrial level, which goes from pulmonary to systemic atrium when the atrioventricular valves are closed, and from systemic to pulmonary when the atrioventricular valves are open. Such a communication between the pulmonary and systemic circulation is necessary and life-saving, for in transposition of the great arteries the two circulations are driven by two separate pumps as opposed to two pumps in series as in the normal circulation (Bonham-Carter, 1967). The policy, therefore, is to create an atrial septal defect in all patients whether a ventricular septal defect or other lesions are present or not. For this reason transposition of the great arteries + ventricular septal defect denotes transposition + ventricular septal defect + balloon atrial septostomy. 


\section{Incidence of transposition of great arteries}

A lecture like this should not be without some reference to the incidence of this lesion. Fontana and Edwards (1962) and Carlgren (1959) give a relative figure of 7 to 8 per cent of the total of congenital heart disease. Taking the incidence of congenital heart disease as being 8 per 1000 live births, though it is probably nearer to 10 per 1000 live births if the trivia are included, at the current birth rate this means we may expect between 300 and 400 infants with transposition of the great arteries to be born annually in the United Kingdom. In this way the total work load caused by this lesion may be calculated.

\section{Effect of palliative operations, including bal- loon atrial septostomy, on natural history of transposition of the great arteries}

In 1950 Blalock and Hanlon introduced the technique of atrial septectomy. Our experience of 178 such operations was that the hospital mortality was 45 per cent overall, the highest risk being in those operated upon under the age of 6 weeks. Though the overall mortality fell from 57 per cent in the earlier years 1958 to 1963 , to 35 per cent in the years 1964 to 1968 , this was mostly due to a decline in the mortality of those operated upon after the age of 6 weeks, which fell from 46 to 18 per cent, while the mortality of those operated upon under 6 weeks fell only from 69 to 61 per cent (Deverall et al., 1969). It was the introduction by Rashkind of balloon atrial septostomy that reduced the mortality in the age group under 6 weeks, as Tynan has shown (Rashkind and Miller, 1966; Tynan, 1968, 1971). Nevertheless, after more than 150 balloon atrial septostomies our mortality while awaiting in-flow 'correction' (Mustard et al., 1964) is still of the order of 25 per cent by the age of 6 months. Nor is this mortality commonly due to inadequate septostomy, though 5 patients have failed to develop a bidirectional shunt at atrial level despite adequate septostomy. It is due to respiratory infection, gastrointestinal disease with dehydration, thromboembolic disorders particularly cerebral, congestive cardiac failure, and pulmonary vascular disease.

The observation of Carr that irreversible vascular disease occurred in the pulmonary arteries of patients with transposition of the great arteries with ventricular septal defect and or persistent ductus before the age of I year, but did not occur until much later in those with transposition + atrial septal defect or in those with transposition with ventricular septal defect and left ventricular outflow tract obstruction has led to further palliative surgery (Bonham-Carter, 1967). Deverall showed that per- sistence of the ductus arteriosus after septectomy appeared to be a contributory factor in causing death from congestive cardiac failure (Deverall et al., 1969). These two things, the danger of the development of irreversible pulmonary vascular disease in transposition of the great arteries + ventricular septal defect \pm persistent ductus and the danger of a persistent ductus arteriosus causing congestive cardiac failure, have led us to the conclusion that after septostomy all infants should be reinvestigated at between 4 and 6 months of age, and if at this time a persistent ductus arteriosus is found or ventricular septal defect of such a size as to raise the pulmonary artery pressure to two-thirds of the systemic level or higher, then the persistent ductus should be ligated and the pulmonary artery banded at that age. This emphasizes the importance of reaching the pulmonary artery in every case at this investigation, for left ventricular outflow tract obstruction may cause an increase in the ventricular pressure without any increase in pulmonary vascular resistance. Stark et al. (1970) reported our results for banding the pulmonary artery in 33 patients with transposition + ventricular septal defect with a mortality of 12 per cent and concluded that this prevented the development or worsening of pulmonary vascular disease if done before the age of I year. This is done despite the fact that we know that spontaneous closure of both persistent ductus arteriosus and ventricular septal defect occurs in transposition of the great arteries. It should be noted that to date we do not seem to have affected the course of pulmonary vascular disease when we have banded the pulmonary artery after the age of I year, and this is why early post-septostomy investigation must be done in transposition + ventricular septal defect with or without persistent ductus arteriosus. As Liebman has shown, the prognosis of transposition of the great arteries + ventricular septal defect + left ventricular outflow tract obstruction is relatively good, and as under these circumstances we do not expect pulmonary vascular disease to develop, it is possible that these children will live and grow until an intraventricular repair using a conduit, as described by Rastelli, may be done (Liebman et al., 1969; Rastelli, 1969). When the three anomalies coexist, palliative surgery to improve the pulmonary blood flow may become necessary to prevent the haemoglobin level and so the blood viscosity from rising to dangerous levels. Our indication for doing a systemic to pulmonary arterial shunt in this situation is a diminishing effort tolerance or a haemoglobin level approaching $20 \mathrm{~g} / \mathrm{I} 00$ $\mathrm{ml}$. We feel this is preferable to attempting intraventricular reconstruction which, if done in infancy, may have to be repeated in later childhood because 
of growth. Though transposition of the great arteries + ventricular septal defect + left ventricular outflow tract obstruction (valvar) may be a congenital lesion it may also apparently develop (Tynan et al., 1969). This left ventricular outflow tract obstruction appears at investigation to be subvalvar, and may have more than one cause, for at times it appears angiographically to be muscular and contractile, and at others, as we have actually seen in three patients at operation, an abnormally attached mitral valve. Its importance lies in the fact that it adds to the surgical risk of inflow 'correction'.

To summarize the management of transposition of the great arteries that has emerged from these observations: (I) balloon atrial septostomy will be done on all patients under the age of 3 months whether ventricular septal defect or other lesions are present. Over 3 months of age the fossa ovalis may be too tough to tear well, and septectomy is preferable. (2) All patients will be fully reinvestigated between the ages of 4 and 6 months. At this investigation it is essential that the pulmonary artery is reached, so that the pulmonary blood flow and pulmonary vascular resistance may be calculated. (3) At this admission all patients with persistent ductus arteriosus will be ligated, and all those with ventricular septal defects in whom the pulmonary artery pressure is greater than two-thirds of systemic will have their pulmonary arteries banded to a pressure of 30-40 mmHg. (4) Those shown to have small single ventricular septal defects will be left until the time of inflow correction, when the defect will be closed.

\section{Effect of definitive surgery on natural history of transposition of the great arteries}

We have already reported our results for the first 200 operations for transposition (Breckenridge et al., 1972). In this group previous atrial septectomy or balloon atrial septostomy had been performed in $8 \mathrm{I}$ per cent. There were 138 patients with transposition + atrial septal defect only, 44 with transposition + ventricular septal defect, and 14 with transposition, ventricular septal defect and left ventricular outflow tract obstruction. The overall mortality was 26.5 per cent, comprising 18 per cent hospital deaths and 8.5 per cent late deaths; the relative mortality in the three groups was 18,43 , and 50 per cent, respectively. The first Mustard's operation was done here in 1965 by Aberdeen and the results in 78 patients with transposition and atrial septal defect only were published by Aberdeen (197I). In the last 59 patients the results have shown improvement in mortality in transposition of great arteries + atrial septal defect $(13 \%)$ and in transposition with ventricular septal defect $(14 \%)$ but not in transposition + ventricular septal defect + left ventricular outflow tract ob- struction which remains at 50 per cent. In the latter group our policy is to temporize, doing, as already suggested, systemic to pulmonary arterial shunts when necessary to allow these children to grow to a size where the intraventricular type of correction is feasible.

The age at which surgically correctable congenital malformations that endanger life ought to be corrected should be the age at which the mortality rate upon the waiting list for correction is not greater than the operative risk. This has led us to lower the age of definitive surgery in transposition + atrial septal defect and transposition + ventricular septal defect (small), so that most patients now have definitive surgery under the age of I year; in the former, 28 such infants have been operated upon consecutively with no deaths, and in the latter 5 such infants with I death.

The problem of transposition + ventricular septal defect + left ventricular outflow tract obstruction is not completely resolved, for the ability at a later age to do an intraventricular outflow correction may be limited by the size of the ventricular septal defect.

Complications of definitive surgery Of the three complications of this type of operation two appear to have a surgical solution, i.e. arrhythmias and patch contraction, while the third, tricuspid incompetence, remains an imponderable. The two surgical modifications which have reduced the incidence of arrhythmias are cannulating the superior vena cava well away from the right atrium or through the appendage which reduces the incidence of atrial flutter and other atrial arrhythmias, and by suturing the patch posterior to the orifice of the coronary sinus which has reduced the incidence of atrioventricular dissociation (Aberdeen, 1971 ; Breckenridge et al., 1972). Because of the problem of flutter early in the series, postoperative patients have all been left on maintenance digoxin. This, with the reduced incidence of flutter, currently appears unnecessary. The original patch used was pericardium and we have evidence of contraction obstructing the superior vena cava in 6 patients, and obstructing the pulmonary venous inflow in 4 patients. A change was made because of this, and recent results have shown an improvement in surgical mortality as has been stated, but it is too early to claim that using a 'dacron' patch will prevent contraction. Tynan investigated the question of tricuspid incompetence in a group of 23 postoperative patients and found the incidence low, but time will have to elapse before a long-term assessment can be made (Tynan, Aberdeen, and Stark, 1972). Further, the assessment of tricuspid incompetence at the original investigations is difficult; because of the postmortem 
finding in two patients who had abnormal tricuspid valves, presumptively congenital, it is clear that some patients with transposition of the great arteries are born with abnormal tricuspid valves (one such has had tricuspid annuloplasty).

\section{Conclusions}

Though our policy is becoming clearer, further experience is needed to define it. For transposition of the great arteries without atrial septal defect it is certain that early balloon atrial septostomy is the correct initial treatment. Because of the possibility of coexisting ventricular septal defect or persistent ductus arteriosus preoperative investigation should be performed between 4 and 6 months; after this all those with a persistent ductus arteriosus should be submitted to ligation, and the pulmonary artery should be banded to prevent pulmonary vascular disease in those with ventricular septal defect whose left ventricular pressure is two-thirds or more of systemic, or who have a significantly raised pulmonary vascular resistance. The Mustard operation is currently being done electively between 8 and 12 months of age in those who have either transposition + atrial septal defect only, and those who have these two anomalies with a small single ventricular septal defect. Those with large or multiple ventricular septal defects will be banded, and left until large enough for intraventricular correction, which means the insertion of a conduit from the right ventricle to the pulmonary artery.

For those with transposition + ventricular septal defect + left ventricular outflow tract obstruction, our results to date have dictated a change of policy. So that these will be left until they are large enough for intraventricular correction, and will have systemic pulmonary arterial shunts as palliative procedures if these are indicated by diminishing effort tolerance or rising haemoglobin levels. There remains the difficult problem of those in whom pulmonary vascular disease has not been prevented by early operation for inflow 'correction', or by banding of the pulmonary artery. It is clear that when the pulmonary vascular resistance is equal to systemic then nothing can be done, but at what level of vascular resistance should operation be refused? The problem here is complicated by the physiological difficulty of calculating pulmonary vascular resistance using the Fick principle, or dilution techniques when there is a known bidirectional shunt (Silove, Tynan, and Simcha, 1972). Using these methods we have been misled into operating upon 4 patients who at necropsy had clearly got irreversible pulmonary vascular disease. Currently we would offer operation to any whose vascular resist- ance in the lungs was less than three-quarters of systemic resistance.

In those who have transposition + ventricular septal defect with increased pulmonary vascular resistance precluding inflow 'correction', we would nevertheless recommend atrial septectomy, which occasionally causes an obvious clinical improvement, and by venting the left atrium may theoretically delay the progress of the pulmonary vascular disease.

It seems then that the objects of future treatment must be to lower the mortality upon the waiting list, by doing definitive surgery earlier, to use all known means for the prevention of pulmonary vascular disease which eventually precludes operation, and to solve the problem of patch contraction.

This lecture is a summary of the work of many people of different disciplines; physicians, physiologists, surgeons, anaesthetists, technicians, and nurses, without whose efforts progress would not have been made, nor would it have been made without a most generous grant from the British Heart Foundation.

\section{References}

Aberdeen, E. (197I). Correction of uncomplicated cases of transposition of the great arteries. British Heart fournal, 33, Suppl., 66.

Blalock, A., and Hanlon, C. R. (1950). The surgical treatment of complete transposition of the aorta and the pulmonary artery. Surgery, Gynecology and Obstetrics, 90, 1.

Boesen, I. (1963). Complete transposition of the great vessels. Importance of septal defects and patent ductus arteriosus. Circulation, 28, 885.

Bonham-Carter, R. E. (1967). A contribution to cardiovascular physiology for the study of complete transposition of the great arteries. Edgar Mannheimer Memorial Lecture. Bulletin of the Association of European Paediatric Cardiologists, 3, 9.

Breckenridge, I. M., Oelert, H., Stark, J., Graham, G. R., Bonham-Carter, R. E., and Waterston, D. J. (1972). Mustard's operation for transposition of the great arteries. Lancet, 1, I140.

Carlgren, L. E. (1959). Incidence of congenital heart disease in children born in Gothenburg - 1941-1950. British Heart fournal, 21, 40.

Deverall, P. B., Tynan, M. J., Carr, I., Panagopoulous, P., Aberdeen, E., Bonham-Carter, R. E., and Waterston, D. J. (1969). Palliative surgery in children with transposition of the great arteries. Fournal of Thoracic and Cardiovascular Surgery, 58, 721 .

Fontana, R. S., and Edwards, J. E. (1962). Congenital Cardiac Disease. Saunders, Philadelphia.

Hoffheinz, H. J., Glaser, E., and Rodewald, G. (1964). Uber die Häufigkeit angeborener Herzfehler im Hamburger Sektionsgut. Zentralblatt für Chirurgie, 89, 326.

Liebman, J., Cullum, L., and Belloc, N. B. (1969). Natural history of transposition of the great arteries; anatomy and birth and death characteristics. Circulation, 40, 237.

Mustard, W. T., Keith, J. D., Trusler, G. A., Fowler, R., and Kidd, L. (1964). The surgical management of transposition of the great vessels. Fournal of Thoracic and Cardiovascular Surgery, 48, 953.

Rashkind, W. J., and Miller, W. W. (1966). Creation of an atrial septal defect without thoracotomy. Fournal of the American Medical Association, 196, 991. 
Rastelli, G. C. (1969). A new approach to 'anatomic' repair of transposition of the great arteries. Mayo Clinic Proceedings, 44, I.

Silove, E. D., Tynan, M. J., and Simcha, A. J. (1972). Thermal dilution measurement of pulmonary and systemic blood flow in secundum atrial septal defect, and transposition of great arteries with intact interventricular septum. British Heart Fournal, 34, 1142.

Stark, J., Tynan, M., Tatooles, C. J., Aberdeen, E., and Waterston, D. J. (1970). Banding of the pulmonary artery for transposition of the great arteries and ventricular septal defect. Circulation, 41 and 42, Suppl. II, I16.

Tynan, M. J. (1968). Balloon atrial septostomy. Archives of Disease in Childhood, 43, 744.

Tynan, M. (197I). Balloon atrial septostomy in the palliative treatment of transposition of the great arteries. Thesis for Doctorate of Medicine, London University.

Tynan, M., Aberdeen, E., and Stark, J. (1972). Tricuspid incompetence after the Mustard operation for transposition of the great arteries. Circulation, 45, Supplement I, I II.

Tynan, M., Carr, I., Graham, G., and Bonham-Carter, R. E. (1969). Subvalvar pulmonary obstruction complicating the postoperative course of balloon atrial septostomy in transposition of the great arteries. Circulation, 39 and 40, Suppl. I, 223.

Requests for reprints to Dr. R. E. Bonham-Carter, Thoracic Unit, The Hospital for Sick Children, Great Ormond Street, London WCIN 3JH. 